\title{
Representation of Women in Advertisements
}

\author{
Dr. Sunita Kumar, School of Business Studies and Social Sciences, Christ University, Bangalore
}

\begin{abstract}
The primary purpose of this paper is to understand people's perception about overt sexuality and objectification of women in advertisements through the ages. Substantiating the content with both - current trending advertisements and previous studies that have been conducted, the research paper analyses the difference in perception of advertisements among generations and brings to light the intentional shift in focus by brands from the features of the brand to the models in the ad. Women are particularly vulnerable to an advertiser's use of representation of people as symbols and are relatively powerless because of male dominance in today's society.
\end{abstract} Index Terms: Overt sexuality, objectification of women, advertising depictions and subordination of women

\section{I.INTRODUCTION}

Marketing is often expressed as a competition for gaining consumer attention. In today's dynamic business environment the primary objective is to attract consumers, but the question remains to what extent can one stoop to gain this momentary attraction. Would it be ethically correct to demean women and position them as sexual objects to evoke a second glance towards the advertisement. Though not universally embraced and held in disdain by many people the use of overt sexual appeal has increased considerably in advertising. Literature has shown that in the long run such explicit portrayals only lead to a massive uproar and negative perception towards the brand. As seen over a period of time various recognized brands such as Nissan and Haagen Daaz have proved the futility in attaining negative publicity by symbolizing the women as sexual objects.

\section{Objectives}

- To conceptually gain insight into the role played by women in sexually appealing ads and to understand consumer perception towards these ads.

- To attain a deeper understanding of the depiction of women in advertisements from the 1990's till date.

\section{METHODOLOGY}

The study understands the role of women as sexual objects through qualitative analysis techniques such as review of literature and analysis of ads.

\section{REVIEW OF LITERATURE}

Elliott, Benfield \& Barlow (1995) conducted a study on "Overt Sexuality in Advertising: A Discourse Analysis of Gender Responses". In this article, objectification of women is one of the prime concerns while talking about overt sexuality in advertisement. This exploratory study investigates the extent to which male and female differ in response to over sexuality using twenty-five women and twenty men, the sample was built using snowballing and with the help of eight focus group interview. The study concludes that even though objectification of men is apparent it is not developed sufficiently to be used as an unusual concept. The study raises problems that need to be addressed particularly with regard to women are looked upon during these advertisements. The study also highlights the difference between the perspective of men and women and also the changing thought process with the newer generation. The study also shows there are liberal values portrayed to some extent of overt sexuality. The primary problem faced by marketers is where to draw the line and there is scope for further study in this field. The research concludes that the use of overt sexuality can be legitimated provided that men and women are equally involved with the sexual action and particularly if the consumer can categorize it as an art.

Blai, Stephenson, Hill \& Green (2006) conducted a study on "Ethics in Advertising: Sex Sells, But Should It?" In this study they try to examine whether or not it is ethical to use sex appeal in advertisements. Though it is a known fact that these advertisements catch the viewer's attention but this attention is limited to the models in the ad and fails to create any brand recognition. The study also finds an increased trend in men being used more as a sex object. Women look at highly explicit print ads more distastefully than their male counterparts. The article also recognizes the fact that the expectation of a print ad displaying strong sexual appeal should yield a significantly less favorable attitude towards the ad, the brand and purchase intention than those ads containing a mild sexual appeal. Sex objectification is in the eye of the beholder therefore leaves the object of effective advertising very challenging. Mager \& Helgeson (2010) conducted a study on "Fifty Years of Advertising images: Some Changing Perspectives on Role Portrayals Along with Enduring Consistencies". The researchers in their study tried to represent a trend towards objective role portrayals of women and tried to evaluate the tacit reflection with some distortion of societal changes in the US during the course of fifty years. The article suggests that increased objectification of women and sometimes even men in advertising may be related to an extent to the increased emphasis US culture has placed on consumerism in the past fifty years. The article primarily evaluates print advertising and its subliminal impact on society. Using a research methodology called semiotic content analysis Goffman identified what would be considered more subtle indication of cultural position, sexuality and sexism. The research identified an increasing trend in women and men positioned in suggestive ways in magazine advertisements and found that the positioning focuses on the body of the model as an integral part of the body of the advertisement. Using the research tools, the authors understood that the 
primary objective of this suggestive positioning was to attract more attention towards the ad.

Huang \& Lowry (2012) conducted a study on "An Analysis of Nudity in Chinese Magazine Advertising: Examining Gender, Racial and Brand Differences" The article shows that female models are more likely to be shown at different levels of nudity than male models as well as the fact that western models are more like to depict this phenomena than Chinese models.

LaTour \& Henthorne (1994) conducted a study on "Ethical Judgments of Sexual Appeals in Print Advertising". This article attempts to examine the impact of potentially controversial sexual appeals as ad stimuli on consumers, their ethical judgment, attitude towards ad, attitude towards brand and purchase intention are analyzed. The data was collected through the use of mall intercept during all hours of mall operations over the course of one week. The study found that the use of a highly sexual theme in a print ad was not well received and considered as less ethically correct than the use of mild sexual version of the same ad. In the study sample both men and women expressed ethical concern over the use of overtly sexual ads.

One of the prime concerns and future scope of study lies in determining the point at which sexual appeal may be viewed as unethical and considered counterproductive. The study also concludes that sexual ad portrayals that have worked well in the past may not be as well received in todays advertising climate because of the focus on moral and ethical issue surrounding female role portrayals in advertising as a feminist issue.

Amir (2007) conducted a study on "Sexual Content on Mainstream TV Advertising: A Cross-cultural Comparison" tries to examine a content analysis of American and Israeli ads on their representation of sexual content in mainstream TV advertisements. The most consistent finding of this article is that both countries explicit behavior for instance intercourse, non-normative conduct for example homosexuality, illegal activity for instance prostitution.

\section{QUALITATIVE ANALYSIS}

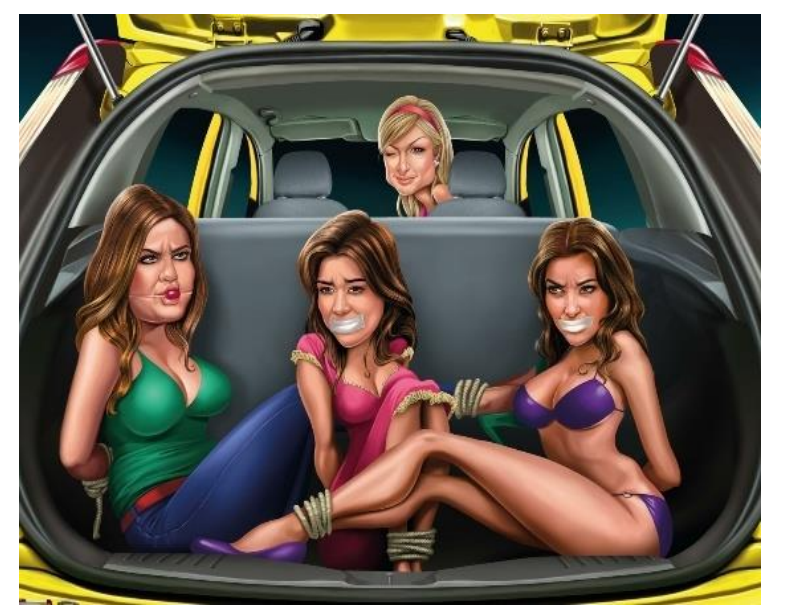

Figure 1. The advertisement was considered as one portraying women in a negative light
One of the primary reasons why this advertisement was considered as one portraying women in a negative light was due to the manner in which women are treated in this ad. The car advertisement focuses on women as something that can be bought by anyone who buys the car rather than highlighting the features of the car. The suggestive clothing and positioning of the women reiterates the universal belief of men being the superior sex.

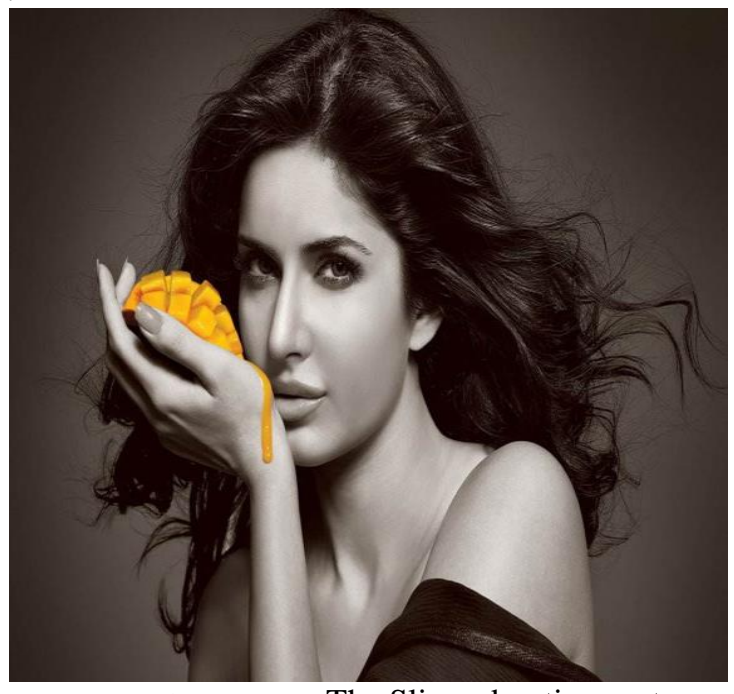

Figure 2. The Slice advertisement

The Slice advertisement uses the sexual connotation associated with certain sweet food items such as chocolates and applies it to mangoes. This sexuality is also evident through the semi-bare Katrina Kaif in the ad.

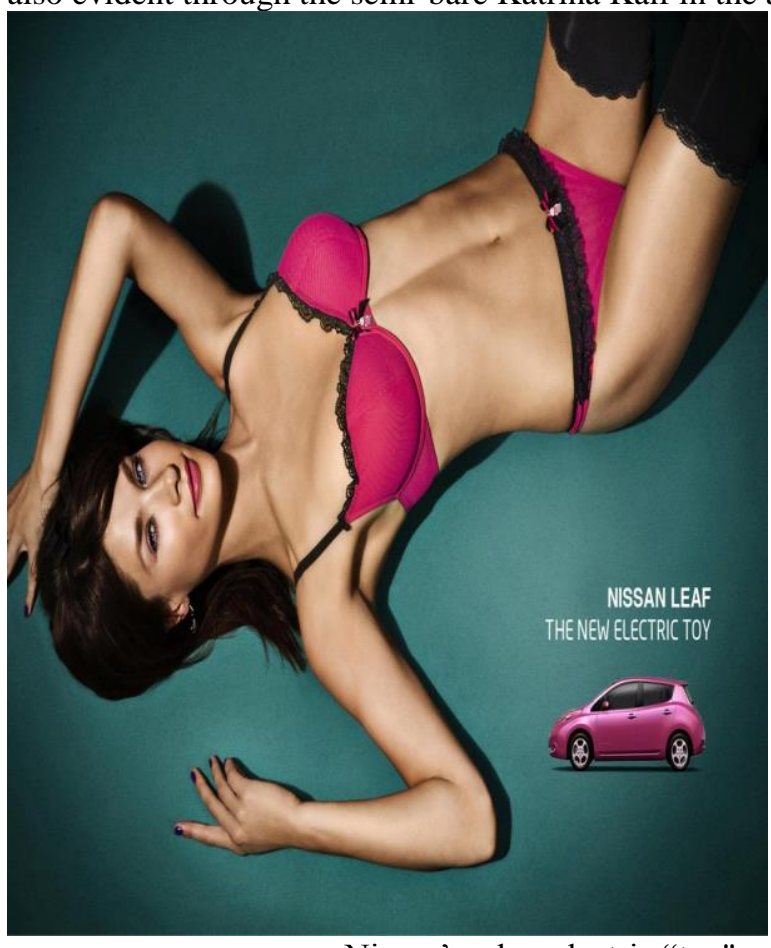

Figure 3. Nissan's ad as electric "toy"

The brand hurts feminist sentiments by blatantly proclaiming women as an electric "toy". Nissan has been criticized through the ages for sexually provocative ads and the means used to attract the consumer attention to their product. This particular ad grabs the consumer attention through the colour sync between the women's lingerie and the colour of car. 


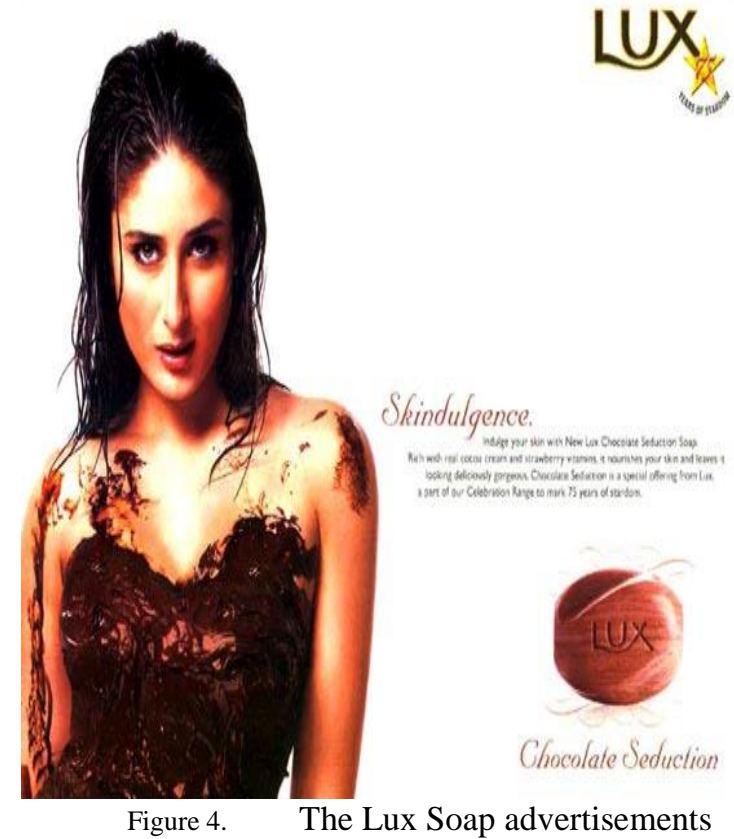

Overtly sexual advertisements like Lux Soap may represent the use of a subconscious symbolic language that recognizes the indirect link between sexuality and a desire for consumer goods. These explicit images in advertisement give women an emancipated choice of consumption meanings.

\section{CONCLUSION}

The paper helps analyze consumer's perspective on overt sexuality and though we have found that the use of sexual appeals attracts consumers it is also believed that the blatant use of such themes build a negative image about the brand in the consumers mind. The study also shows how these advertisements are primarily targeted at younger groups that have a broader perspective and a more open mindset.

\section{FUTURE SCOPE OF STUDY}

In order to add value to the current research various qualitative research techniques such as focus group interviews will give researchers greater insight into the consumer mindset. Moreover in the future a more detailed study can be conducted to analyze ads over the past three decades to gain perspective on the consumers evolving thought process and the changing pattern in advertisement.

\section{REFERENCES}

[1] Alexander, W. M., \& Judd, B. (1978). Do nudes in ads enhance brand recall? Journal of Advertising Research, 18, 47-51.

[2] Amir, H. (2007). Sexual content on mainstream tv advertising: A cross- cultural comparison. Springer, 201-210.

[3] Almog, O. (2004). Preida misrulik: Shinui arachim bachevra hayisraelit (Hebrew: Farewell Srulik: Value changes in Israeli society). Haifa: University of Haifa Press.
[4] Avraham, E., \& First, A. (2003). "I buy American": The American image as reflected in Israeli advertising. Journal of Communication, 53, 282-299.

[5] Blair, J., Stephenson, J., Hill, K., \& Green, J. (2006). Ethics in advertising: Sex sells, but should it?. Journal of Legal, Ehtical and Regulatory Issues, 9(1/2), 109118.

[6] Bloch, L. R., \& Lemish, D. (2003). The megaphone effect: The international diffusion of cultural media via the USA. Communication Yearbook, 27, 159-190.

[7] Boddewyn, J. J. (1991). Controlling sex and decency in advertising around the world. Journal of Advertising, 20(4), 25-35.

[8] Bretl, D., \& Cantor, J. (1988). The portrayal of men and women in U.S. television commercials: A recent content analysis and trends over 15 years. Sex Roles, 18, 595-609.

[9] Cohen, J. (2001). Defining identification: A theoretical look at the identification of audiences with media characters. Mass Communication and Society, 4, 245264.

[10] Dolliver, M. (1999). Is there too much sexual imagery in advertising? Adweek, 21, 22.

[11] Elliott, R., Benfield, A., \& Barlow, M. (1995). Overt sexuality in advertising: A discourse analysis of gender responses. Journal of Consumer Policy, 187217.

[12] Farrar, K. M., Kunkel, D., Biely, E., Eyal, K., Fandrich, R., \& Donnerstein, E. (2003). Sexual messages during prime-time programming. Sexuality and Culture, 7(3), 7-36.

[13] Fisher, W. A., Cook, I. J., \& Shirkey, E. C. (1994). Correlates of support for censorship of sexual, sexually violent, and violent media. Journal of Sex Research, 31, 229-240.

[14] Fisher, D. A., Hill, D. L., Grube, J. W., \& Gruber, E. L. (2004). Sex on American television: An analysis across program genres and network types. Journal of Broadcasting \& Electronic Media, 48, 529-553.

[15] Frith, K. T., Cheng, H., \& Shaw, P. (2004). Race and beauty: A comparison of Asian and Western models in women magazines advertisements. Sex Roles, 50, 5361.

[16] Frith, K. T., \& Mueller, B. (2003). Advertising and societies. NY: Peter Lang.

[17] Ganahl, D. J., Prinsen, T. J., \& Baker-Netzley, S. (2003). A content analysis of prime-time commercials: A contextual framework of gender representation. Sex Roles, 49, 545-552.

[18] Goffman, E. (1979). Gender advertisements. New York: Harper \& Row.

[19] Greenberg, B. S. (1988). Some uncommon television images and the drench hypothesis. In S. Oskamp (Ed.), Television as a social issue (pp. 88-102). Newbury Park, CA: Sage.

[20] Groom, C., \& Pennebaker, J. (2005). The language of love: Sex, sexual orientation, and language use in online personal advertisements. Springer, 52(7/8), 447-461.

[21] Gunter, B. (2002). Media sex: What are the issues? Mahwah, NJ: Erlbaum.

[22] Hetsroni, A. (2001). What do you really need to know to be a millionaire-The question of knowledge in quiz shows from America and Israel. Communication Research Reports, 18, 418-428.

[23] Hetsroni, A. (2007a). Israeli advertising: From oriental dilettantism to professional westernism. In E. C. Alozie (Ed.), Advertising and emerging economies: A contextual exploration. Spokane, WA: Marquette. 
[24] Hetsroni, A. (2007b). Three decades of sexual content on prime-time network programming: A longitudinal meta-analytic review, Journal of Communication, 57, 318-348.

[25] Hofstede, G. (2001), Culture's consequences; Comparing values, behaviors, institutions and organizations across nations (2nd ed.). Thousand Oaks, CA: Sage.

[26] Huang, Y., \& Lowry, D. (2012). An analysis of nudity in chinese magazine advertising: Examining gender, racial and brand differences. Springer, 440-452.

[27] Kassaarjian, H. H. (1977). Content analysis in consumer research. Journal of Consumer Research, 4, 8-18.

[28] Keenan, K. L. (1994). Advertising. In E. K. Thomas \& B. H. Carpenter (Eds.), Handbook on mass media in the United States (pp. 3-18). Westport, CT: Greenwood.

[29] LaTour, M. S., Pitts, R. E., \& Snook-Luther, D. C. (1991). Female nudity, arousal, and ad response: An experimental investigation. Journal of Advertising, 19(4), 51-62.

[30] Lin, C. A. (1997). Beefcake versus cheesecake in the 1990s: Sexist portrayals of both genders in television commercials. Howard Journal of Communication, 8, 237-249.

[31] Lin, C. A. (1998). Uses of sex appeals in prime-time television commercials. Sex Roles, 38, 461-475.

[32] Mager, J., \& Helgeson, J. (2010). Fifty years of advertising images: Some changing perspectives on role portrayals along with enduring consistencies. Springer, 238-252.

[33] Maguire, B., Sandage, D., \& Weatherby, G. A. (2000). Violence, morality and television commercials. Sociological Spectrum, 20, 121-1

[34] Mittal, B. (1994). Public assessment of TV advertising: Faint praise and harsh criticism. Journal of Advertising Research, 34, 35-53.

[35] Nelson, M. R., \& Paek, H. J. (2005). Cross-cultural differences in sexual advertising content in a transnational women's magazine. Sex Roles, 53(5/6), 371-383.

[36] Ogburn, W. F. (1964). The hypothesis of cultural lag. In A. Etzioni \& E. Etzioni (Eds.), Social change: Sources, patterns and consequences, (pp. 459-462). New York: Basic Books.

[37] Piron, F., \& Young, M. (1996). Consumer advertising in Germany and the United States: A study of sexual explicitness and cross-gender contact. Journal of International Consumer Marketing, 8, 211-228.

[38] Reichert, T. (2003b). The prevalence of sexual imagery in ads targeted to young adults. Journal of Consumer Affairs, 37, 403-412. 